REVIEW ARTICLE

\title{
Physical activity in the context of the COVID-19 pandemic: Research profiling and mapping
}

\author{
Mateusz Tomanek ${ }^{\mathrm{CDE}}$, Andrzej Lis ${ }^{\mathrm{ABCD}}$ \\ Faculty of Economic Sciences and Management, Nicolaus Copernicus University in Toruń, Poland
}

Authors contribution: A - Study design; B - Data collection; C - Bibliometric analysis; D - Manuscript preparation; E - Funds collection

\begin{abstract}
Background The aim of the study is to profile and map the scientific output in research on physical activity in the and Study Aim COVID-19 context. The study makes an attempt to response to the three following questions: (1) What are the leading contributors (countries, research institutions, authors and source titles) to research production in the field? (2) What are the core references? (3) What are the leading thematic areas / research fronts?

Material and We used the Scopus database as a source of bibliometric data for the research sampling process and Methods employed a combination of bibliometric methods, including research profiling and selected science mapping methods, i.e. co-word analysis and direct citation analysis, in order to achieve the aim of the study and provide responses to the study questions. Science mapping processes were supported with VOSviewer software.

Results: $\quad$ Research profiling indicates that the main contributors to scientific output on physical activity in the COVID-19 context are scholars and research institutions from countries, which have been heavily affected by the pandemic such as: the United States, the United Kingdom, Italy, Spain, Brazil. Certainly, the reports from China, which was the first nation to suffer from COVID-19 and associated epidemic restrictions, constitute an important input, too. The core references in research on physical activity in the COVID-19 context may be grouped into three categories aimed at: (1) investigating the consequences of pandemic restrictions on physical activity, (2) analysing the outcomes of physical activity for other variables, and (3) providing recommendations for practising home-based physical activity during COVID-19 confinement. Science mapping of the research field conceptual structure indicates the following thematic areas / research fronts in research on physical activity in the COVID-19 context: (1)'pandemic and its outcomes', (2) 'physical activity during self-isolation', (3) 'health behaviour', (4) 'food habits', (5) 'mental health', (6) 'adults and the pandemic'.

Conclusions: The study contributes to development of physical activity theory by profiling and mapping research conducted in the context of the COVID-19 pandemic. Through mapping the scientific output, the paper points out the leading contributors and core references, and makes an attempt to identify leading thematic areas / research fronts. Discovering the main signposts may be useful for all the researchers planning and designing research within the field. Moreover, mapping research fronts indicates them the topics attracting attention of the academia and potential research gaps.

Keywords: $\quad$ physical activity, COVID-19, bibliometrics, research profiling, science mapping.
\end{abstract}

\section{Introduction}

There is no doubt that 2020 will be remembered as the year of the COVID-19 pandemic. At the outbreak of the pandemic, the lack of sufficient information about threats and possible counter-measures against the virus deepened the feeling of uncertainty. In consequence, the responses to the increase in the number of infection cases varied across the countries. Lockdown restrictions ranged from closing hotels, restaurants or schools to imposing home isolation and travel restrictions [1,2]. Simultaneously, scholars around the world started investigating social, economic and health consequences of the pandemic and lockdown. The impact of the spreading pandemic and associated restrictions on physical activity seems to be one of the emerging streams of COVID-19 related research. For instance, Tison et al. (2020) [3] measured the changes in the average daily step count between February and June 2020 in 187 countries observing both a sharp decrease in

(c) Mateusz Tomanek, Andrzej Lis, 2021

doi:10.15561/20755279.2021.0301 physical activity and significant regional differences. In addition to the studies focusing on direct consequences of the pandemic confinement on the physical activity intensity, some other related themes have been explored e.g. medical benefits of physical activity during the pandemic discussed by Dwyer et al. (2020) [4] or the role of social media, as a substitute of sport, for physical activity analysed by Hayes (2020) [5]. Nevertheless, in spite of the growing number of publications, the variety of themes, streams and aspects in the research field has not been mapped from the bibliometric perspective, so far.

Thus, the aim of the study is to profile and map the scientific output in research on physical activity in the COVID-19 context. The study makes an attempt to response to the three following questions: (1) What are the leading contributors (countries, research institutions, authors and source titles) to research production in the field? (2) What are the core references? (3) What are the leading thematic areas / research fronts? In the remainder of the paper, firstly, data sampling and research 
methodology are explained. Secondly, the findings of general publication profiling and thematic profiling are presented. Thirdly, the key contributors, the core references and the leading thematic areas in research on physical activity in the COVID-19 context are explored and discussed.

\section{Material and Methods}

\section{Data Sources and Research Sample}

We used the Scopus database as a source of bibliometric data for the research sampling process. As of 15 January 2021, we searched for the following conjunction of phrases: 'physical activity' (in titles of publications) and 'covid-19' / 'sars-cov-2' / 'coronavirus' (in titles, keywords and abstracts). We retrieved 229 records meeting searching criteria. They were published in 2020 (215 items; 94\%) and 2021 (14; 6\%). The majority of them are journal articles $(165 ; 72 \%)$, written in English (221; 97\%). The publications comprising the research sample represent 19 various subject areas, defined by Scopus. Medicine is the subject area of the highest number of included items (167). The followers are: Psychology (35 items), Environmental Science (34) and Health Professions (33). Detailed characteristics of the research sample are provided in Table 1.

\section{Method of Study}

In order to achieve the aim of the study and provide responses to study questions, we employed a combination of bibliometric methods, including research profiling [6] and selected science mapping [7] methods, i.e. coword analysis [8] and direct citation analysis [9]. Among the components of research profiling [10], we used the general publication profiling framework to identify leading contributors to research on physical activity in the COVID-19 context. Direct citation analysis supported general publication profiling to identify core (i.e. the most cited) references and discover research fronts in the field. For the purposes of thematic profiling, we triangulated the findings from direct citation analysis with the results of co-word analysis, namely high-frequency keywords co-occurrence analysis. In the process of designing and conducting research we benchmarked earlier bibliometric articles published in Physical Education of Students $[11,12]$. The processes of co-word analysis and direct citation analysis were conducted with the support of VOSviewer software $[13,14]$. As the principle, the association strength normalization method and default values of layout and clustering parameters were used. Increasing the minimum number of publications within a cluster up to 5 items, while identifying research fronts through direct citation analysis, was the only exception.

\section{Results}

\section{General Publication Profiling}

The first step of the analysis is focused on identifying leading contributors to research on physical activity in the COVID-19 context, including the most productive and influential countries, research institutions, authors and the source titles of the first choice for publication. We employed the two measures to recognize the key contributors i.e. the number of publications to assess their research productivity and the citation count to evaluate their impact on the research field. The detailed data presenting the most productive and influential countries, research institutions and authors as well as the source titles of the first choice to publish the research findings related to physical activity in the COVID-19 context are provided in Table 2.

The second step of analysis aims at identifying the core references in research on physical activity in the COVID-19 context. As of 15 January 2021, 229 publications comprising the research sample have received 998 citations. Within the sample, there are 105 items cited at least once, and 21 publications with 10 and more citations. The publications with minimum one citation have been analysed with the use of the method of direct citation analysis in order to identify the core references. Figure 1 presents the item density map of such publications in research on physical activity in the COVID-19 context, highlighting the publications with the highest number of received citations.

\section{Thematic Profiling}

The third step of analysis shifts the attention to identifying the leading thematic areas within the field. The methods of co-word analysis (in this particular case: co-occurrence analysis of high frequency keywords) and direct citation analysis are employed to map research fronts. The publications comprising the research sample provide 1,248 keywords, among which there are 838 expressions, which occurred only once. According to the formula provided by Donohue (1974) [15], cited after Guo et al. (2017) [16], the number of high-frequency

Table 1. Research sample characteristics

\begin{tabular}{ll}
\hline Category & Items (N) \\
\hline Subject area & Medicine (167); Psychology (35); Environmental Science (34); Health Professions (33); Nursing \\
(top 10 items) & (22); Social Sciences (19); Neuroscience (13); Biochemistry, Genetics and Molecular Biology \\
& (12); Agricultural and Biological Sciences (10); Energy (6) \\
Document type & Article (165); Note (17); Letter (15); Review (15); Editorial (11); Erratum (3); Short Survey (2); \\
& Data Paper (1) \\
Language & English (221); Spanish (7); Portuguese (4); Chinese (1); French (1); Italian (1); Japanese (1) \\
\hline
\end{tabular}

Source: Own study based on data retrieved from Scopus (15 January 2021). 
Table 2. General publication profiling of research on physical activity in the COVID-19 context

\begin{tabular}{|c|c|c|}
\hline Category & Top Items (number of publications) & Top Items (number of citations) \\
\hline Country & $\begin{array}{l}\text { United States (47); United Kingdom (38); Italy } \\
\text { (33); Spain (29); Brazil (27); Australia (15); } \\
\text { China (15); Canada (14); Austria (9); Chile (9); } \\
\text { France (9); Germany (9); Portugal (9) }\end{array}$ & $\begin{array}{l}\text { United States (479); Italy (243); Denmark (239); } \\
\text { China (233); United Kingdom (196); Spain (145); } \\
\text { Canada (145); Tunisia (134); France (124); Brazil } \\
(114)\end{array}$ \\
\hline $\begin{array}{l}\text { Research } \\
\text { Institution }\end{array}$ & $\begin{array}{l}\text { Anglia Ruskin University, UK (9); University of } \\
\text { Palermo, Italy (7); Ulster University, UK (7); } \\
\text { University of Southern Denmark, Denmark } \\
\text { (6); Shanghai University of Sport, China (6); } \\
\text { University of Murcia, Spain (5); Iowa State } \\
\text { University, US (5); University of Sao Paolo, } \\
\text { Brazil (5); University of Limerick, Ireland (5); } \\
\text { Federal University of Sao Paolo, Brazil (5) }\end{array}$ & $\begin{array}{l}\text { Shanghai University of Sport, China (230); University } \\
\text { of Southern Denmark, Denmark (230); Arizona State } \\
\text { University, US (171); Oregon Research Institute, US } \\
\text { (171); Shanghai Municipal Education Commission, } \\
\text { China (171); Wilamette University, US (171) }\end{array}$ \\
\hline Author & $\begin{array}{l}\text { Smith, L., Anglia Ruskin University, UK (8); } \\
\text { Meyer, J., lowa State University, US (5); } \\
\text { Grabovac, I., Medical University of Vienna, } \\
\text { Austria (4) }\end{array}$ & $\begin{array}{l}\text { Nassis, G.P., Shanghai University of Sport, China } \\
\text { and University of Southern Denmark (169); } \\
\text { Ainsworth, B.E. Shanghai University of Sport, China } \\
\text { and Arizona State University, US (167); Chen, P., } \\
\text { Shanghai University of Sport, China (167); Harmer, } \\
\text { P., Willamette University US (167); Li, F., Oregon } \\
\text { Research Institute, US (167), Mao, L., Shanghai } \\
\text { University of Sport, China and Shanghai Municipal } \\
\text { Education Commission, China (167) }\end{array}$ \\
\hline $\begin{array}{l}\text { Source } \\
\text { Title }\end{array}$ & $\begin{array}{l}\text { International Journal of Environmental } \\
\text { Research and Public Health (26); Frontiers in } \\
\text { Psychology (12); Journal of Sport and Health } \\
\text { Science (7); Nutrients (7); Sustainability } \\
\text { Switzerland (6); Sleep Medicine (4) }\end{array}$ & $\begin{array}{l}\text { Journal of Sport and Health Science (187); } \\
\text { International Journal of Environmental Research and } \\
\text { Public Health (135); Nutrients (116); Managing Sport } \\
\text { and Leisure (54); Obesity (45); Heliyon (35); Progress } \\
\text { in Cardiovascular Diseases (34); Sustainability } \\
\text { Switzerland (34) }\end{array}$ \\
\hline
\end{tabular}

Source: Own study based on data retrieved from the Scopus (15 January 2021).

keywords to be selected for analysis is 42 , each of them of the minimum number of occurrences equal to 18. Nevertheless, as the research field is still within its emergence phase, we decided to include into analysis 66 expressions, which have received at least 10 citations. The cluster density visualization of high-frequency keywords co-occurrence analysis is presented in Figure 2, and the composition of clusters is detailed in Table 3. In the map, the size of the keywords corresponds to the number of received citations, and the spatial proximity portrays the strength of relatedness between the items.

In order to increase quality and accuracy of mapping of the thematic areas in the field, we combined co-word analysis with direct citation analysis. As some of 105 publications, which were cited at least once, taken for direct citation analysis are not connected to each other, for the purposes of identifying research fronts, we used the largest set of connected items, numbering 47 publications. The cluster density visualization of the groupings representing research fronts in the field is presented in Figure 3, and their composition is detailed in Table 4.

\section{Discussion}

\section{Leading Contributors}

In total, 60 countries have contributed to research production on physical activity in the COVID-19 context.
Among them, the threshold of 5 and more publications has been achieved by 21 countries and, and the level of 10 publications - by 9 nations. The United States is found to be the most productive country in the research field with 47 publications. Other substantive contributors are: the United Kingdom (38 items), Italy (33), Spain (29) and Brazil (27). What is worth noticing, all the aforementioned countries have been among the most affected by the COVID-19 pandemic. The top research institutions of the highest number of published works are: Anglia Ruskin University (9 items), University of Palermo (7), and Ulster University (7). In regard to the number of received citations, the leaders are: Shanghai University of Sport (230 citations) and the University of Southern Denmark (230). The most prolific authors are: Smith, L. from Anglia Ruskin University (8 items), Meyer, J. affiliated at Iowa State University (5), and Grabovac, I. representing Medical University of Vienna, Austria (4). The scholars, whose publications have received the highest number of citations are the authors of the note on "the need to maintain regular physical activity while taking precautions" against COVID-19, published in Journal of Sport and Health Science in the early days of the pandemic (online publication in February 2020) [19], who are affiliated at Chinese, American and Danish institutions, i.e.: Nassis, G.P. (Shanghai University of Sport 


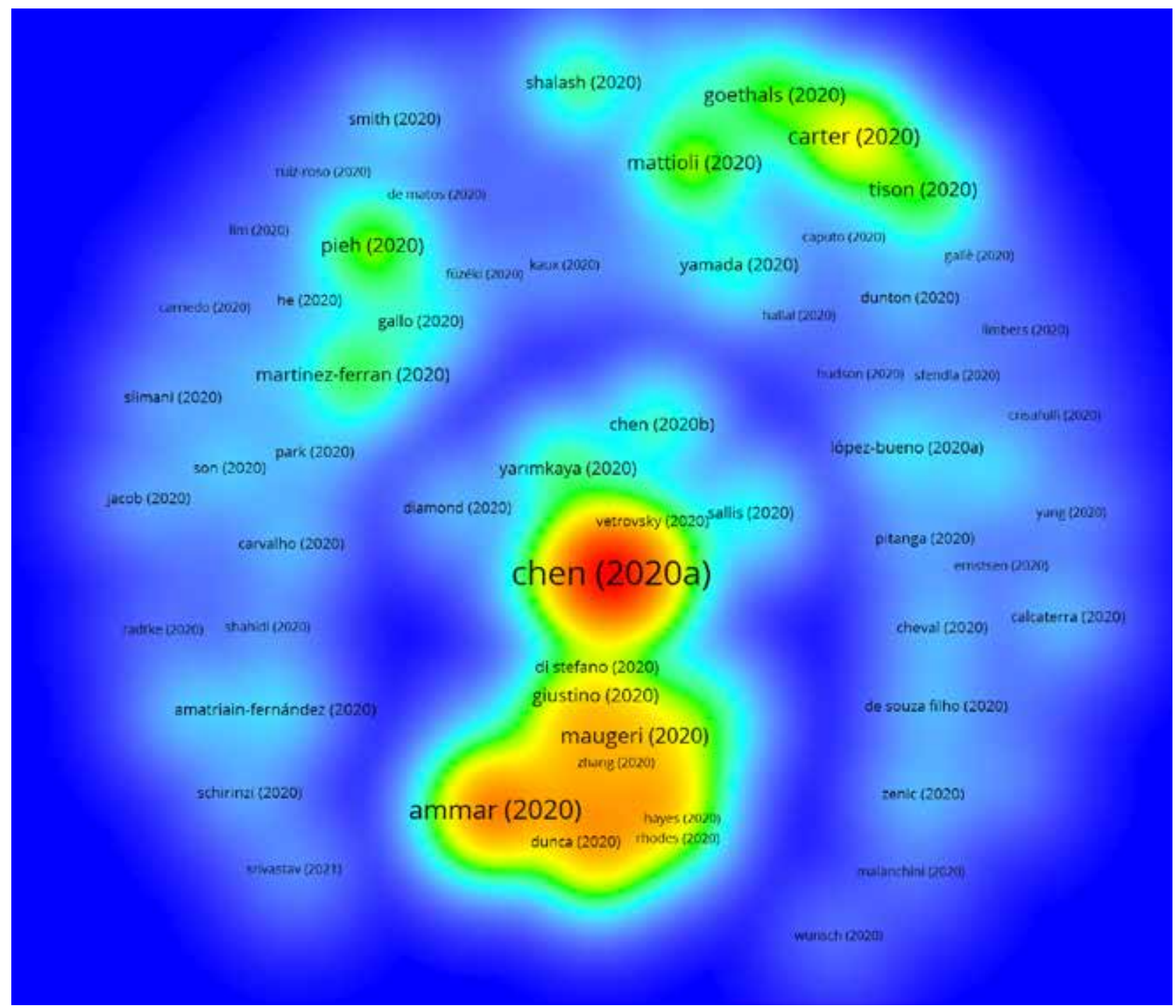

Figure 1. Core references in research on physical activity in the COVID-19 context (direct citation analysis, item density visualisation, weights - citations): Source: Own study based on data retrieved from Scopus and analysed with VOSviewer (15 January 2021).

Table 3. Clusters of high-frequency keywords in research on physical activity in the COVID-19 context

\begin{tabular}{ll}
\hline $\begin{array}{l}\text { Cluster number } \\
\text { / label / colour / } \\
\text { number of items }\end{array}$ & Keywords \\
\hline $\begin{array}{l}\text { Cluster 1 / } \\
\text { 'pandemic and its } \\
\text { outcomes' / red / } \\
\mathrm{N}=26\end{array}$ & $\begin{array}{l}\text { betacoronavirus; child; coronavirus disease 2019; coronavirus infection; coronavirus } \\
\text { infections; diet; exercise; human; humans; obesity; pandemic; pandemics; physical } \\
\text { inactivity; physiology; pneumonia viral; priority journal; procedures; quarantines; risk } \\
\text { factor; screen time; sedentary lifestyle; social isolation; sport; virology; virus pneumonia; } \\
\text { walking }\end{array}$ \\
\hline $\begin{array}{l}\text { Cluster 2 / 'health } \\
\text { behaviours' / green } \\
\text { / N=22 }\end{array}$ & $\begin{array}{l}\text { adolescent; adult age; aged; article; body mass; controlled study; cross-sectional studies; } \\
\text { physical activity questionnaire; major clinical study; male; middle-aged; questionnaire; } \\
\text { sars-cov-2; sedentary behaviour; surveys and questionnaires; young adults }\end{array}$ \\
\hline $\begin{array}{l}\text { Cluster } 3 \text { / 'mental } \\
\text { health' / blue / N=18 }\end{array}$ & $\begin{array}{l}\text { anxiety; coronavirus; covID-19; depression; epidemic; health status; lifestyle; lockdown; } \\
\text { mental health; physical activity; psychological well-being; psychology; public health; quality } \\
\text { of life; sleep; social distancing; stress; viral disease }\end{array}$ \\
\hline
\end{tabular}

Source: Own study based on data retrieved from Scopus and analysed with VOSviewer (15 January 2021). 


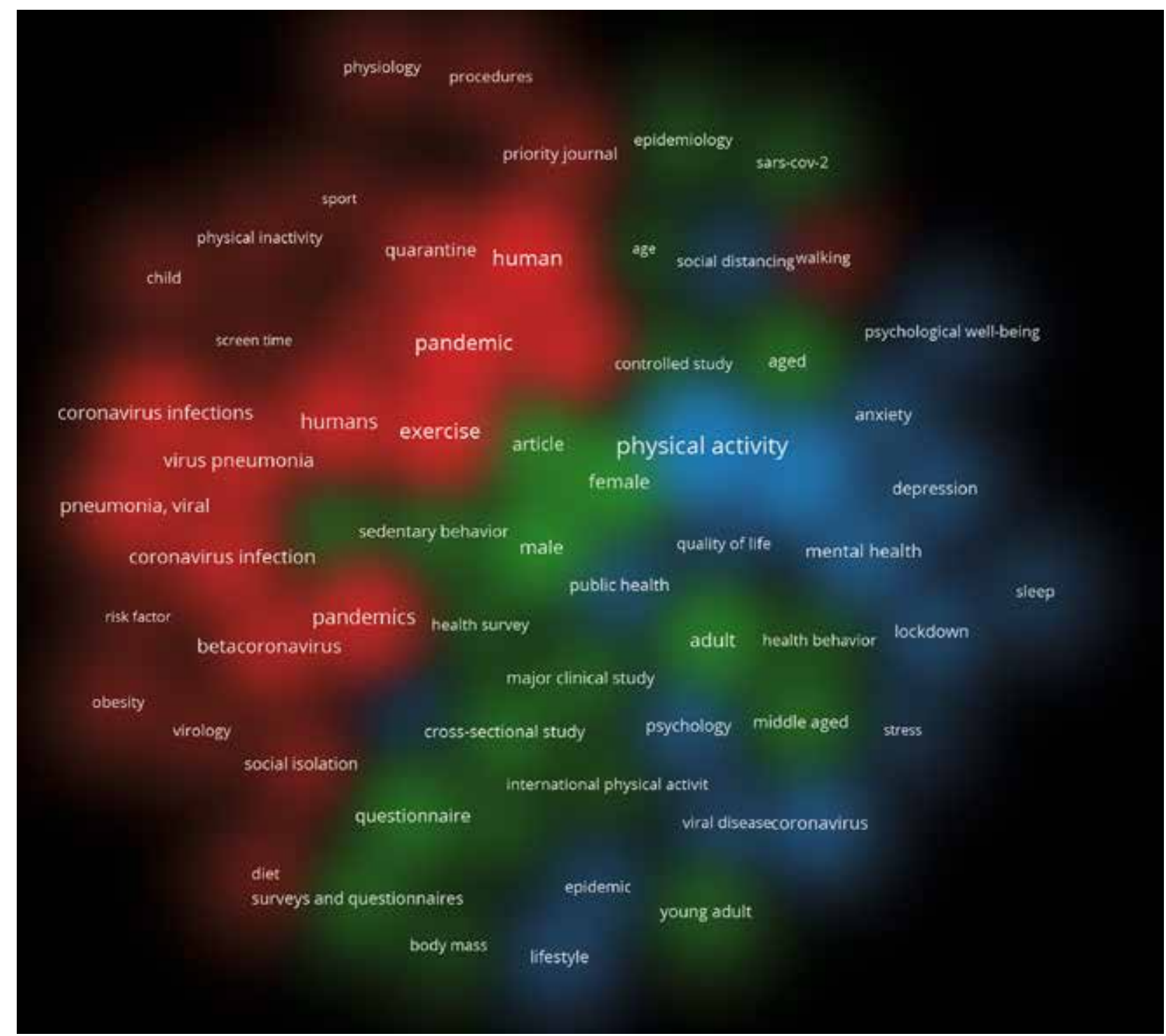

Figure 2. Fronts in research on physical activity in the COVID-19 context (co-word analysis, cluster density visualisation, weights - citations): Source: Own study based on data retrieved from Scopus and analysed with VOSviewer (15 January 2021).

and the University of Southern Denmark), Ainsworth, B.E. (Shanghai University of Sport and Arizona State University), Chen, P. (Shanghai University of Sport), Harmer, P. (Willamette University); Li, F. (Oregon Research Institute), and Mao, L. (Shanghai University of Sport and Shanghai Municipal Education Commission). Among the source titles, which published the highest number of articles related to the topic are: International Journal of Environmental Research and Public Health (26 publications), and Frontiers in Psychology (12). The journals, whose articles have been most cited, include: Journal of Sport and Health Science (187 citations), and International Journal of Environmental Research and Public Health (135).

\section{Core References}

The note by Chen et al. (2020a) [19] on "the need to maintain regular physical activity while taking precautions" against COVID-19, published in Journal of Sport and Health Science in the early days of the pandemic (online publication in February 2020), is the most cited work within the sample (156 citations). Other highly cited publications are the studies of: effects of counter pandemic restrictions on eating behaviours and physical activity across Asia, Africa and Europe by Ammar et al. (2020) [47] (78 citations), "associations between psychological distress and changes in selected health behaviours", including physical activity, during the pandemic in Australia by Stanton et al. (2020) [46] (57 citations), and "recommendations for home-based physical training" by Hammami et al. (2020) [39] (53 citations). Among the core references in the field, we consider the papers cited at least 10 times. These publications may be grouped into three categories aimed at: (1) investigating the consequences of pandemic restrictions on physical activity, (2) analysing the outcomes of physical activity for other variables e.g. immunity, vitamin D status, glycaemic, and mental health, and (3) providing recommendations for practising homebased physical activity during COVID-19 confinement 


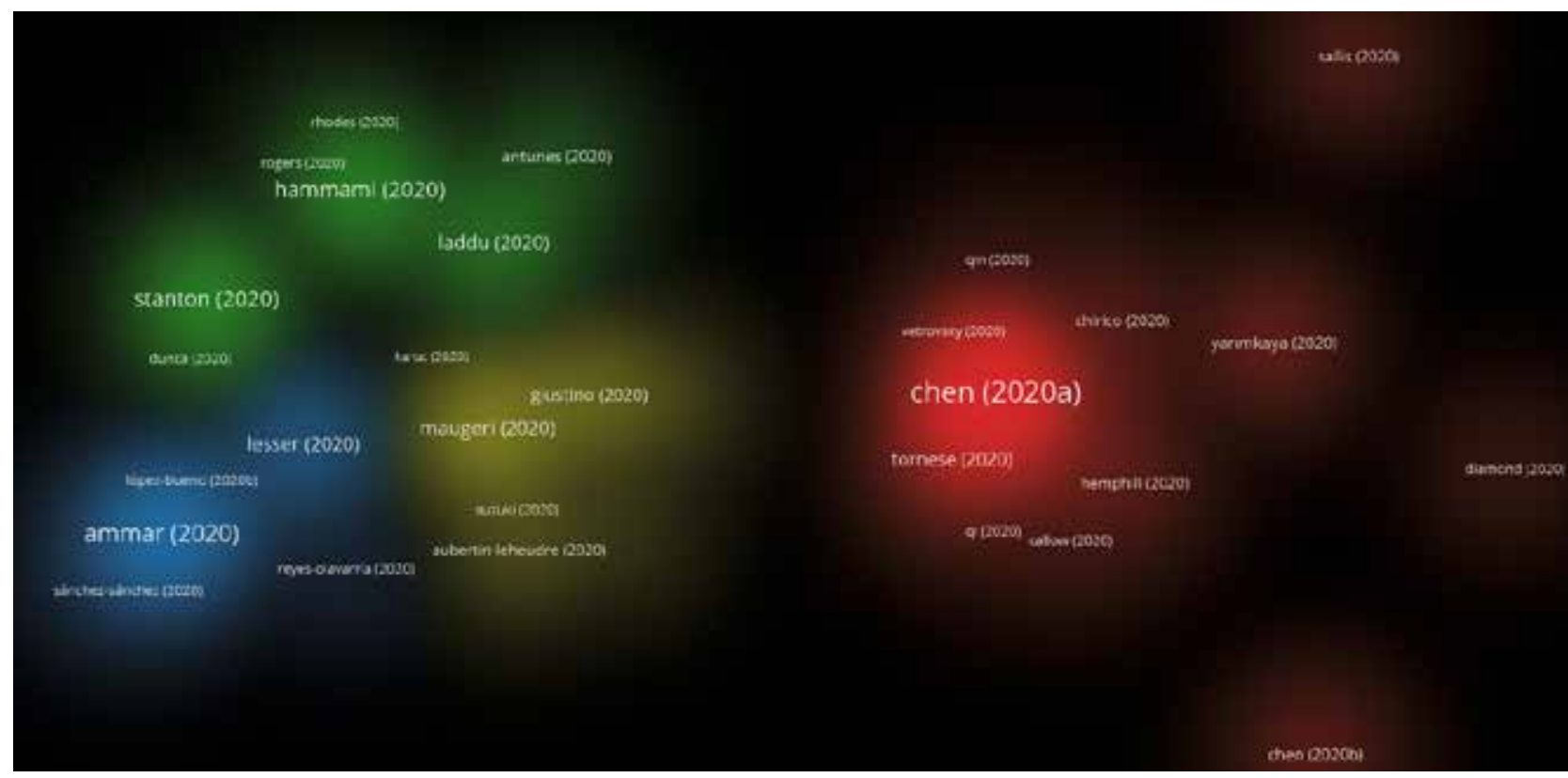

Figure 3. Fronts in research on physical activity in the COVID-19 context (direct citation analysis, cluster density visualisation, weights - citations): Source: Own study based on data retrieved from Scopus and analysed with VOSviewer (15 January 2021).

Table 4. Clusters of core references in research on physical activity in the COVID-19 context

\begin{tabular}{|c|c|}
\hline $\begin{array}{l}\text { Cluster number } \\
\text { / label / colour / } \\
\text { number of items }\end{array}$ & References \\
\hline $\begin{array}{l}\text { Cluster } 1 \text { / 'physical } \\
\text { activity during self- } \\
\text { isolation' / red / } \mathrm{N}=20\end{array}$ & $\begin{array}{l}\text { Callow et al. (2020) [17]; Castañeda-Babarro et al. (2020) [18]; Chen et al. (2020a) [19]; } \\
\text { Chen et al. (2020b) [20]; Chirico et al. (2020) [21]; Di Sebastiano et al. (2020) [22]; } \\
\text { Diamond and Waite (2020) [23]; Esentürk (2020) [24]; Fröberg (2020) [25]; Hemphil et al. } \\
\text { (2020) [26]; Jurak et al. (2020) [27]; Kaushal et al. (2020) [28]; Qi et al. (2020) [29]; Qin et } \\
\text { al. (2020) [30]; Rosales et al. (2020) [31]; Sallis et al. (2020) [32]; Sekulic et al. (2020) [33]; } \\
\text { Tornese et al. (2020) [34]; Vetrovsky et al. (2020) [35]; Yarımkaya and Esentürk (2020) } \\
\text { [36] }\end{array}$ \\
\hline $\begin{array}{l}\text { Cluster } 2 \text { / 'mental } \\
\text { health' / green / N=11 }\end{array}$ & $\begin{array}{l}\text { Antunes et al. (2020) [37]; Dunca et al. (2020) [38]; Hammami et al. (2020) [39]; Hayes } \\
\text { (2020) [5]; Karuc et al. (2020) [40]; Laddu et al. (2020) [41]; Ng (2020) [42]; Nigro et al. } \\
\text { (2020) [43]; Rhodes et al. (2020) [44]; Rogers et al. (2020) [45]; Stanton et al. (2020) [46] }\end{array}$ \\
\hline $\begin{array}{l}\text { Cluster } 3 \text { / 'food } \\
\text { habits' / blue / N=8 }\end{array}$ & $\begin{array}{l}\text { Ammar et al. (2020) [47]; Lesser and Nienhuis (2020) [48]; López-Bueno (2020) [49]; } \\
\text { Reyes-Olavarria (2020) et al. [50]; Romero-Blanco et al. (2020) [51]; Ruíz-Roso et al. } \\
\text { (2020) [52]; Schuch et al. (2020) [53]; Sánchez-Sánchez et al. (2020) [54] }\end{array}$ \\
\hline $\begin{array}{l}\text { Cluster } 4 \text { / 'adults and } \\
\text { the pandemic' / green } \\
\text { / N=8 }\end{array}$ & $\begin{array}{l}\text { Aubertin-Leheudre and Rolland (2020) [55]; Di Stefano et al. (2020) [56]; Dwyer et al. } \\
\text { (2020) [4]; Giustino et al. (2020) [57]; Katewongsa et al. (2020) [58]; Maugeri et al. (2020) } \\
\text { [59]; Suzuki et al. (2020) [60]; Zhang et al. (2020) [61] }\end{array}$ \\
\hline
\end{tabular}

Source: Own study based on data retrieved from Scopus and analysed with VOSviewer (15 January 2021).

\section{(cf. Figure 4).}

The first category of the core references is focused on the consequences of pandemic restrictions on physical activity and it comprises the already mentioned studies by Ammar et al. (2020) [47] and Stanton et al. (2020) [46]. Among other publications, Lesser and Nienhuis (2020) [48] (38 citations) present the findings of their research conducted in April and May 2020, on the impact of social distancing and closing of sport facilities on physical activity and well-being of Canadians. The Italian study of Maugeri et al. (2020) [59] (35 citations) proves that home isolation resulted in decrease in weekly energy expenditure associated with physical activity in all age categories, and particularly among men. Mattioli et al. (2020) [62] (27 citations) point out that stress and depression caused by home confinement result in unhealthy diet behaviours and less intensive physical activity. In their qualitative study, Goethals et al. (2020) [63] (23 citations) assess the impact of quarantine on physical activity of the elderly living in France and the authors recommend to enhance physical activity of senior citizens through providing them with a set of simple exercises to be practiced individually at 


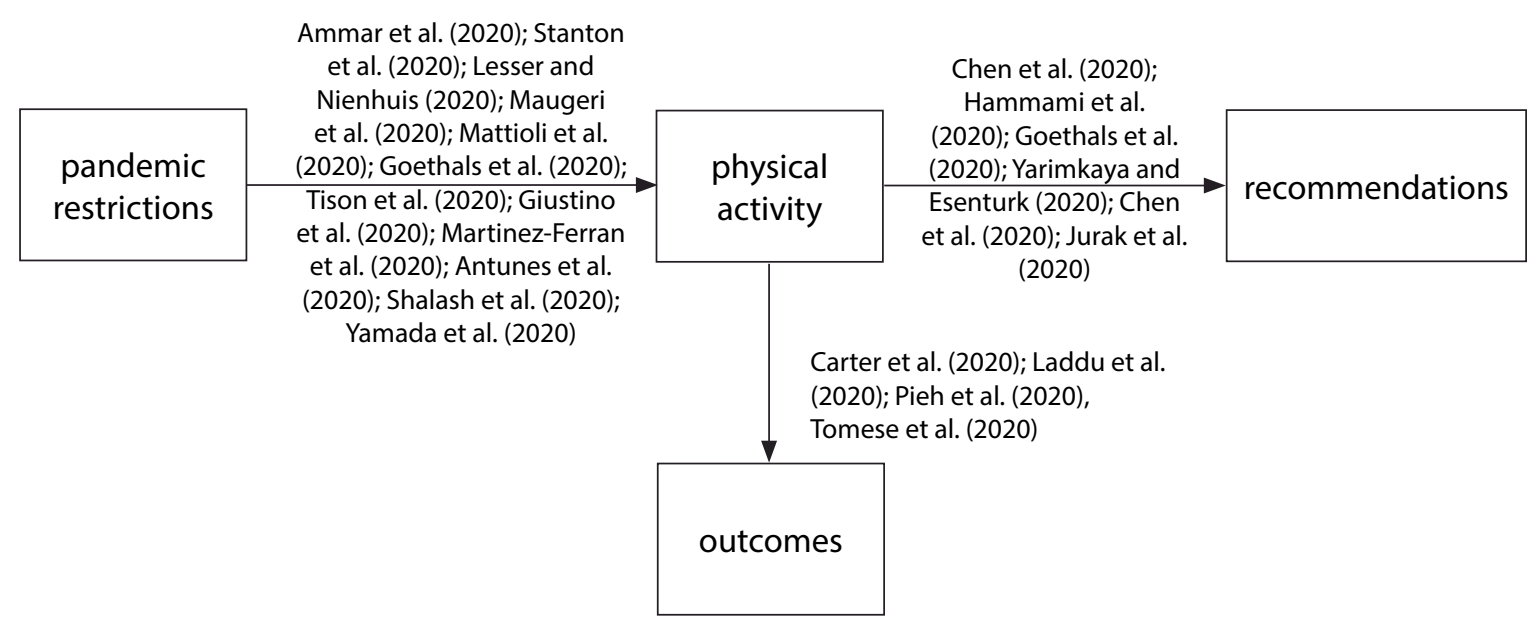

Figure 4. Categorization of the core references in research on physical activity in the COVID-19 context: Source: Own study based on data retrieved from Scopus (15 January 2021).

home. Tison et al. (2020) [3] (22 citations) analyse the changes in the step count among more than 450 thousand people from 187 countries and indicate significant regional changes due to national counter-pandemic strategies e.g. Italy noticed decrease by $48.7 \%$, while Sweden only by $6.9 \%$. Giustino et al. (2020) [57] (20 citations) report that decrease in energy expenditure among the professionally active Sicilians negatively impacts physical activity, in particular among males and overweight people. MartinezFerran et al. (2020) [64] (19 citations) analyse research reports on metabolic changes, lack of physical activity and overfeeding to assess the metabolic consequences of social isolation during the pandemic in regard to changes in diets and physical activity. Antunes et al. (2020) [37] (14 citations) claim that negative psychological consequences may result not only from the lockdown itself but also from the need of adaptation to the new situation, as imposed restrictions require obeying new rules and norms in personal, social and professional activities. Shalash et al. (2020) [65] (14 citations) tested how the pandemic influenced the quality of life among the Parkinon's disease patients, who reported negative outcomes in regard to mental health, physical activity and health care. Yamada et al. (2020) [66] (11 citations) surveyed Japanese older adults and measured their physical activity between June and April 2020. Similarly to other authors, they confirmed decrease in physical activity, which may result in growth of disabilities during and after the pandemic.

The second category of the core references analyses the consequences of practicing physical activity during the pandemic for other variables. Laddu et al. (2020) [41] (34 citations) indicate that regular physical activity may strengthen immunity. Carter et al. (2020) [67] (44 citations) claim that physical activity, particularly while practiced outdoor, is a favourable factor for vitamin D status, which improves immunity against respiratory infections. Tornese et al. (2020) [34] (25 citations) validate a positive influence of in-home physical activity on controlling glycaemic in type-1 diabetes mellitus among teenagers. Pieh et al. (2020) [68] (26 citations), who analyse, among others, the impact of physical activity on mental health during the COVID-19 lockdown in Austria, point out an increase in symptoms of depression and fear during the pandemic. The restrictions are found to be particularly stressful for the young adults, women, the unemployed and people of the low income.

The third category of the core references in the field provides recommendations for practising home-based physical activity during COVID-19 confinement and it includes the aforementioned works by Chen et al. (2020a) [19], Hammami et al. (2020) [39], and Goethals et al. (2020) [63]. Among other publications in this category, Yarımkaya and Esentürk (2020) [36] focus their research on children with autism spectrum disorders. The authors analyse their situation during the pandemic and propose a set of physical exercises to be practiced at home. Chen et al. (2020b) [20] (11 citations) provide recommendations for physical activity of the youth and children in regard to the three following areas: aerobic activities, strength training and bone strengthening. Jurak et al. (2020) [27] (10 citations) recommend practicing physical activity of low- or medium intensity for at least 60 minutes per day, including 15 minutes of outdoor activity (e.g. in a garden or on a balcony).

\section{Thematic Areas}

Co-word analysis indicates the three following thematic areas in research on physical activity in the COVID-19 context, which we labelled as: (1) 'pandemic and its outcomes', (2) 'health behaviour', (3) 'mental health'. The keywords comprising Cluster 1 are directly related with the SARS-CoV-2 coronavirus, the COVID-19 pandemic and their outcomes resulting from social distancing and physical inactivity. The expressions grouped within Cluster 1 manifest a 'wide', generalist perspective to exploring the impact of the pandemic on physical activity, and are likely to be associated with early studies in the field. Clusters 2 and 3 are focused on more specified topics i.e. health behaviours and mental health respectively. We hypothesize that they may represent studies conducted in later stages of the pandemic among 
the enlarging population of those who recovered from COVID-19 or suffered from social distancing and lockdown restrictions.

The results of direct citation analysis point out the four clusters of publications focused on the following themes: (1) 'physical activity during self-isolation', (2) 'mental health', (3) 'food habits', (4) 'adults and the pandemic'. Cluster 1, labelled as 'physical activity during self-isolation', includes papers published mainly in health science journals. In their communique issued in February 2020, Chen et al. (2020a) [19] list possible areas of research on the impact of COVID-19 on physical activity and outcomes. For instance, they notice that prolonged periods of self-isolation at home may result in lowering the intensity of physical activity, feeling of fear and depression, which consequently may lead to a wide range of chronic diseases. Cluster 1 includes papers disseminating the findings from research on the scope of physical activity. For instance, Di Sebastiano et al. (2020) [22] measured, with the use of ParticipACTION application, the level of physical activity before and after imposing social distancing restrictions in Canada. Chirico et al. (2020) [21] conducted a similar study among the population of Italy. Kaushal et al. (2020) [28] investigated how the access to the sport equipment at home influenced decisions made by Americans to participate in physical activity.

Cluster 2, consisting of 11 publications, concentrates on the issues of 'mental health'. To mention a few examples, Antunes et al. (2020) [37] claim that negative psychological consequences may result not only from the lockdown itself but also from the need of adaptation to the new situation, as imposed restrictions require obeying new rules and norms in personal, social and professional activities. Dunca et al. (2020) [38] conducted the online questionnaire survey among American twins in order to investigate the relationship between perceived change of physical activity and mental health in the context of the COVID-19 pandemic. Stanton et al. (2020) [46] analyse the association between psychological stress and changes in health behaviours of Australians. Their study encompasses such aspects as: depression, fear, stress, physical activity, sleep, alcohol consumption and smoking.

Food habits are the theme of Cluster 3. SánchezSánchez et al. (2020) [54] investigate food habits of Spanish population before and during COVID-19. They notice that Mediterranean diet slight gains some popularity in the pandemic, while a rise in consumption of 'unhealthy' food (alcohol, snacks, sweets) is noticed. Ammar et al. (2020) [47] suggest that quarantine may be considered as a factor increasing the risk of consuming low quality food. They observe that confined people consume more unhealthy food comparing to the period before the COVID-19 outbreak. What is interesting, their study indicates simultaneously a slight decrease in binge drinking during the pandemic. A high level of consumption of processed food in the pandemic in Italy, Spain and Latin America is reported by Ruíz-Roso et al.
(2020) [52]. It is worth noticing that highly-processed food consumption is typical of poor societies as this kind of food is usually relatively cheap.

Cluster 4, labelled as 'adults and the pandemic', presents the findings of the studies, which take into account the age factor. The interest in the elderly may be observed in research conducted by Suzuki et al. (2020) [60], who investigate how restrictions in public health influence physical activity, subjective well-being and health-related quality of life. Aubertin-Leheudre and Rolland (2020) [55] indicate the need to remember about physical activity of the elderly and offering them simple physical exercises to be practiced at home. Giustino et al. (2020) [57], who studied the professionally active Sicilians, report that decrease in energy expenditure negatively impacts physical activity, in particular among males and overweight people. The research conducted in Thailand shows a similar fall in physical activity. Katewongsa et al. (2020) [58] claims that such a situation may result from a lower priority given to promotion of health lifestyle, while in the early weeks of the pandemic the efforts were concentrated on countering the spread of the coronavirus.

An interesting tendency is observed in regard to research methodologies employed to study the issues of physical activity in the context of the COVID-19 pandemic. Before the pandemic outbreak, papers published in journals representing the disciplines of medicine, health science or sport studies were characterized by the employment of sophisticated quantitative methods and techniques. During the pandemic, the shift from quantitative to qualitative research is noticed. Laboratory experiments were replaced by online questionnaire surveys based on subjective responses of informants. Thus, due to social distancing, the use of online applications to monitor physical activity may be recommended to support data collection in order to objectively asses the level of physical activity.

\section{Conclusions}

In response to the first research question, we have identified the leading contributors (countries, research institutions, authors and source titles) to research on physical activity in the COVID-19 context. The countries, which have contributed with the highest number of publications are: the United States, the United Kingdom, Italy, Spain and Brazil. All the aforementioned countries have been among the most affected by the COVID-19 pandemic. A similar tendency is observed among the research institutions with the highest number of published works or received citations - they mainly represent China (Shanghai University of Sport, Shanghai Municipal Education Commission), where the outbreak of COVID-19 happened or the countries, which heavily suffered from the pandemic e.g. the United States (Arizona State University, Iowa State University, Oregon Research Institute, Wilamette University), the United Kingdom (Anglia Ruskin University, Ulster University), Italy (University of Palermo), Spain (University of Murcia), Brazil (University of Sao Paolo, Federal University of 
Sao Paolo). Lee Smith from Anglia Ruskin University, who published 8 articles, is recognized as the most prolific author. The scholars, whose publications have received the highest number of citations are the authors of the note on "the need to maintain regular physical activity while taking precautions" against COVID-19 published in the early days of the pandemic in February 2020 [19]. The leading journals publishing research on physical activity in the COVID-19 context are: International Journal of Environmental Research and Public Health (by number of published articles) and Journal of Sport and Health Science (by the number of received citations).

In response to the second research question, we have identified and explored the core references in research on physical activity in the COVID-19 context. The aforementioned note by Chen et al. (2020a) [19] on "the need to maintain regular physical activity while taking precautions" against COVID-19 is the most cited work within the sample. The identified core references may be grouped into three categories aimed at: (1) investigating the consequences of pandemic restrictions on physical activity, (2) analysing the outcomes of physical activity for other variables e.g. immunity, vitamin D status, glycaemic, and mental health, and (3) providing recommendations for practising home-based physical activity during COVID-19 confinement.

In response to the third research question, we have identified and explored the leading thematic areas / research fronts in research on physical activity in the COVID-19 context. The three following areas have been mapped with the use of co-word analysis of highfrequency keywords: (1) 'pandemic and its outcomes', (2) 'health behaviour', (3) 'mental health'. The results of direct citation analysis indicate the four clusters of publications focused on the following themes: (1) 'physical activity during self-isolation', (2) 'mental health', (3) 'food habits', (4) 'adults and the pandemic'.

The study contributes to development of physical activity theory by profiling and mapping research conducted in the context of the COVID-19 pandemic. Through mapping the scientific output, it points out the key contributors and core references, and makes an attempt to identify leading thematic areas / research fronts. Discovering the main signposts may be useful for all the researchers planning and designing research within the field. Moreover, mapping research fronts indicates them the topics attracting attention of the academia and potential research gaps.

Discussing the research findings, there is a need to consider limitations of the study and indicate the lines of effort for further research. Firstly, methodological limitations should be mentioned. We have tried to triangulate research methods to ensure an appropriate level of objectivity. In our study we employed both coword analysis and direct citation analysis to identify and explore research fronts in the field. Among citation analysis methods, direct citation is known as effective in discovering emerging fronts [69]. Nevertheless, in the future, following the development of the research field, the replication of this part of the study is recommend with the use of other citation analysis methods, which show a higher level of accuracy in mapping science [70] such as: bibliographic coupling and co-citation analysis. These two methods could be also used to triangulate the mapping of the intellectual structure of the research field and discovering the most influential publications. Secondly, limitations regarding the research sampling process should be unveiled. Although Scopus is a recognized source of high quality bibliometric data, it may omit some important publications, especially those published in languages other than English. Moreover, due to the novelty of the research field the number of items taken for analysis $(\mathrm{N}=229)$ is relatively small for bibliometric studies. Thus, we recommend to replicate the study as the field becomes more developed and to use other sources of bibliometric data for the research sampling process.

\section{Highlights}

- The publications on physical activity in the COVID-19 context represent 19 various subject areas, defined by Scopus. Medicine is the subject area of the highest number of included items. The followers among subject areas are: Psychology, Environmental Science and Health Professions.

- The countries, which have contributed with the highest number of publications are: the United States, the United Kingdom, Italy, Spain and Brazil. All the aforementioned countries have been among the most affected by the COVID-19 pandemic.

- The top research institutions of the highest number of published works are: Anglia Ruskin University, University of Palermo, and Ulster University. In regard to the number of received citations, the leaders are: Shanghai University of Sport and the University of Southern Denmark.

- The leading journals publishing research on physical activity in the COVID-19 context are: International Journal of Environmental Research and Public Health (by number of published articles) and Journal of Sport and Health Science (by the number of received citations).

- The note by Chen et al. (2020a) [19] on "the need to maintain regular physical activity while taking precautions" against COVID-19, published in Journal of Sport and Health Science in the early days of the pandemic (online publication in February 2020), is the most cited work within the sample.

- The core references in research on physical activity in the COVID-19 context may be grouped into three categories aimed at: (1) investigating the consequences of pandemic restrictions on physical activity, (2) analysing the outcomes of physical activity for other variables e.g. immunity, vitamin D status, glycaemic, and mental health, and (3) providing recommendations for practising home-based physical activity during COVID-19 confinement.

- Science mapping of the research field conceptual structure indicates the following thematic areas / 
research fronts in research on physical activity in the COVID-19 context: (1) 'pandemic and its outcomes', (2) 'physical activity during self-isolation', (3) 'health behaviour', (4) 'food habits', (5) 'mental health', (6) 'adults and the pandemic'.

\section{Conflicts of Interest}

The authors declare no conflict of interest.

\section{References}

1. Punn NS, Sonbhadra SK, Agarwal S. Monitoring COVID-19 social distancing with person detection and tracking via fine-tuned YOLO v3 and Deepsort techniques 2020. arXiv:2005.01385

2. de Matos DG, Aidar FJ, de Almeida-Neto PF, Moreira OC, de Souza RF, Marçal AC, et al. The impact of measures recommended by the government to limit the spread of coronavirus (COVID-19) on physical activity levels, quality of life, and mental health of Brazilians. Sustain, 2020;12:art. 9072. https://doi.org/10.3390/su12219072

3. Tison GH, Avram R, Kuhar P, Abreau S, Marcus GM, Pletcher MJ, et al. Worldwide effect of COVID-19 on physical activity: A descriptive study. Ann Intern Med, 2020;173:767-70. https://doi.org/10.7326/M20-2665

4. Dwyer MJ, Pasini M, De Dominicis S, Righi E. Physical activity: Benefits and challenges during the COVID-19 pandemic. Scand J Med Sci Sport, 2020;30:1291-4. https://doi.org/10.1111/sms.13710

5. Hayes M. Social media and inspiring physical activity during COVID-19 and beyond. Manag Sport Leis, 2020:1-8. https://doi.org/10.1080/23750472.2020.1794939

6. Porter AL, Kongthon A, Lu J-CC. Research profiling: Improving the literature review. Scientometrics, 2002;53:351-70. https://doi.org/10.1023/A:1014873029258

7. Zupic I, Čater T. Bibliometric methods in management and organization. Organ Res Methods 2015;18:429-72. https://doi.org/10.1177/1094428114562629

8. He Q. Knowledge discovery through co-word analysis. Libr Trends, 1999;48:133-59.

9. Smith LC. Citation analysis. Libr Trends, 1981;30:83106.

10. Martinez H, Jaime A, Camacho J. Relative absorptive capacity: A research profiling. Scientometrics, 2012;92:657-74. https://doi.org/10.1007/s11192-012-0652-6

11. Tomanek M, Lis A. Managing information on the physical education research field: Bibliometric analysis. Phys Educ Students, 2020;24:213-26. https://doi.org/10.15561/20755279.2020.0404

12. Lis A, Tomanek M. Mapping the intellectual and conceptual structure of physical education research: Direct citation analysis. Phys Educ Students, 2021;25(2):67-84. https://doi.org/10.15561/20755279.2021.0201

13. van Eck NJ, Waltman L. Software survey: VOSviewer, a computer program for bibliometric mapping.

2010;84:523-38. https://doi.org/10.1007/s11192-009-0146-3

14. van Eck NJ, Waltman L. VOSviewer Manual. 2020.

15. Donohue JC. Understanding Scientific Literature: $A$ Bibliometric Approach. Cambridge: MIT Press; 1974.

16. Guo D, Chen H, Long R, Lu H, Long Q. A co-word analysis of organizational constraints for maintaining sustainability. Sustainability, 2017;9:art. 1928. https://doi.org/10.3390/su9101928

17. Callow DD, Arnold-Nedimala NA, Jordan LS, Pena GS, Won J, Woodard JL, et al. The mental health benefits of physical activity in older adults survive the COVID-19 pandemic. Am J Geriatr Psychiatry, 2020;28:1046-57. https://doi.org/10.1016/j.jagp.2020.06.024

18. Castañeda-Babarro A, Coca A, ArbillagaEtxarri A, Gutiérrez-Santamaría B. Physical activity change during COVID-19 confinement. Int $J$ Environ Res Public Health, 2020;17:1-10. https://doi.org/10.3390/ijerph17186878

19. Chen P, Mao L, Nassis GP, Harmer P, Ainsworth BE, Li F. Coronavirus disease (COVID-19): The need to maintain regular physical activity while taking precautions. J Sport Heal Sci, 2020;9:103-4. https://doi.org/10.1016/j.jshs.2020.02.001

20. Chen P, Mao L, Nassis GP, Harmer P, Ainsworth BE, Li F. Returning Chinese school-aged children and adolescents to physical activity in the wake of COVID-19: Actions and precautions: COVID-19 and school physical activity. J Sport Heal Sci, 2020;9:322-4. https://doi.org/10.1016/j.jshs.2020.04.003

21.Chirico A, Lucidi F, Galli F, Giancamilli F, Vitale J, Borghi S, et al. COVID-19 Outbreak and Physical Activity in the Italian Population: A Cross-Sectional Analysis of the Underlying Psychosocial Mechanisms. Front Psychol, 2020;11:2100. https://doi.org/10.3389/fpsyg.2020.02100

22.Di Sebastiano KM, Chulak-Bozzer T, Vanderloo LM, Faulkner G. Don't Walk So Close to Me: Physical Distancing and Adult Physical Activity in Canada. Front Psychol, 2020;11:1895. https://doi.org/10.3389/fpsyg.2020.01895

23.Diamond R, Waite F. Physical activity in a pandemic: A new treatment target for psychological therapy. Psychol Psychother Theory Res Pract, 2021;94:357-64. https://doi.org/10.1111/papt.12294

24.Esentürk OK. Parents' perceptions on physical activity for their children with autism spectrum disorders during the novel Coronavirus outbreak. International Journal of Developmental Disabilities, 2020:1-12. https://doi.org/10.1080/20473869.2020.1769333

25.Fröberg A. The COVID-19 pandemic: The importance of physical activity among faculty members. Journal of American College Health, 2020:1-4. https://doi.org/10.1080/07448481.2020.1817037

26. Hemphill NM, Kuan MTY, Harris KC. Reduced physical activity during COVID-19 
pandemic in children with congenital heart disease. Can J Cardiol, 2020;36:1130-4. https://doi.org/10.1016/j.cjca.2020.04.038

27. Jurak G, Morrison SA, Leskošek B, Kovač M, Hadžić V, Vodičar J, et al. Physical activity recommendations during the coronavirus disease-2019 virus outbreak. J Sport Heal Sci, 2020;9:325-7. https://doi.org/10.1016/j.jshs.2020.05.003

28. Kaushal N, Keith NC, Aguiñaga S, Hagger MS. Social cognition and socioecological predictors of home-based physical activity intentions, planning, and habits during the COVID-19 pandemic. Behav Sci (Basel), 2020;10:art. 133. https://doi.org/10.3390/bs10090133

29. Qi M, Li P, Moyle W, Weeks B, Jones C. Physical activity, health-related quality of life, and stress among the Chinese adult population during the COVID-19 pandemic.IntJEnvironResPublicHealth,2020;17:1-10. https://doi.org/10.3390/ijerph17186494

30. Qin F, Song Y, Nassis GP, Zhao L, Dong Y, Zhao C, et al. Physical activity, screen time, and emotional wellbeing during the 2019 novel coronavirus outbreak in China. Int J Environ Res Public Health, 2020;17:1-16. https://doi.org/10.3390/ijerph17145170

31. Rosales CK, Erazo PV, Valderrama JF, González JB, Terneus DH, Stagno RU, et al. Sport COVID-19 orientations: Recommendations for return to physical activity and sports in children and adolescents. Rev Chil Pediatr, 2020;91:1-16. https://doi.org/10.32641/rchped.vi91i7.2782

32. Sallis JF, Adlakha D, Oyeyemi A, Salvo D. An international physical activity and public health research agenda to inform coronavirus disease-2019 policies and practices. $J$ Sport Heal Sci, 2020;9:328-34. https://doi.org/10.1016/j.jshs.2020.05.005

33. Sekulic D, Blazevic M, Gilic B, Kvesic I, Zenic N. Prospective analysis of levels and correlates of physical activity during COVID-19 pandemic and imposed rules of social distancing; gender specific study among adolescents from Southern Croatia. Sustain, 2020;12:art. 4072. https://doi.org/10.3390/SU12104072

34. Tornese G, Ceconi V, Monasta L, CarlettiC, Faleschini E, Barbi E. Glycemic control in type 1 diabetes mellitus during COVID-19 quarantine and the role of in-home physicalactivity.Diabetes TechnolTher, 2020;22:462-7. https://doi.org/10.1089/dia.2020.0169

35. Vetrovsky T, Frybova T, Gant I, Semerad M, Cimler R, Bunc V, et al. The detrimental effect of COVID-19 nationwide quarantine on accelerometer-assessed physical activity of heart failure patients. ESC Hear Fail, 2020;7:2093-7. https://doi.org/10.1002/ehf2.12916

36. Yarımkaya E, Esentürk OK. Promoting physical activity for children with autism spectrum disorders during Coronavirus outbreak: benefits, strategies, and examples. International Journal of Developmental Disabilities 2020:1-6. https://doi.org/10.1080/20473869.2020.1756115
37. Antunes R, Frontini R, Amaro N, Salvador R, Matos $\mathrm{R}$, Morouço P, et al. Exploring lifestyle habits, physical activity, anxiety and basic psychological needs in a sample of Portuguese adults during COVID-19. Int $J$ Environ Res Public Health, 2020;17:1-13. https://doi.org/10.3390/ijerph17124360

38. Dunca GE, Aver AR, Seto E, Tsang S. Perceived change in physical activity levels and mental health during COVID-19: Findings among adult twin pairs. PLoS One, 2020;15. https://doi.org/10.1371/journal.pone.0237695

39.Hammami A, Harrabi B, Mohr M, Krustrup P. Physical activity and coronavirus disease 2019 (COVID-19): specific recommendations for home-based physical training. Managing Sport and Leisure, 2020:1-6. https://doi.org/10.1080/23750472.2020.1757494

40. Karuc J, Sorić M, Radman I, Mišigoj-Duraković M. Moderators of change in physical activity levels during restrictions due to COVID-19 pandemic in young urban adults. Sustain, 2020;12:art. 6392. https://doi.org/10.3390/SU12166392

41.Laddu DR, Lavie CJ, Phillips SA, Arena R. Physical activity for immunity protection: Inoculating populations with healthy living medicine in preparation for the next pandemic. Progress in Cardiovascular Diseases, 2021;64:102-4. https://doi.org/10.1016/j.pcad.2020.04.006

42. $\mathrm{Ng} \mathrm{K}$. Adapted physical activity through COVID-19. Eur J Adapt Phys Act 2020;13:1-3. https://doi.org/10.5507/EUJ.2020.003

43. Nigro E, Polito R, Alfieri A, Mancini A, Imperlini E, Elce A, et al. Molecular mechanisms involved in the positive effects of physical activity on coping with COVID-19. Eur J Appl Physiol, 2020;120:2569-82. https://doi.org/10.1007/s00421-020-04484-5

44. Rhodes RE, Liu S, Lithopoulos A, Zhang CQ, Garcia-Barrera MA. Correlates of perceived physical activity transitions during the COVID-19 pandemic among Canadian adults. Appl Psychol Heal Well-Being, 2020;12:1157-82. https://doi.org/10.1111/aphw.12236

45.Rogers NT, Waterlow NR, Brindle H, Enria L, Eggo RM, Lees S, et al. Behavioral Change Towards Reduced Intensity Physical Activity Is Disproportionately Prevalent Among Adults With Serious Health Issues or SelfPerception of High Risk During the UK COVID-19 Lockdown. Front Public Health, 2020;8:575091. https://doi.org/10.3389/fpubh.2020.575091

46. Stanton R, To QG, Khalesi S, Williams SL, Alley SJ, Thwaite TL, et al. Depression, anxiety and stress during COVID-19: Associations with changes in physical activity, sleep, tobacco and alcohol use in Australian adults. Int J Environ Res Public Health, 2020;17:1-13. https://doi.org/10.3390/ijerph17114065

47.Ammar A, Brach M, Trabelsi K, Chtourou H, Boukhris O, Masmoudi L, et al. Effects of COVID-19 Home Confinement on Eating Behaviour and Physical Activity: Results of the ECLB-COVID19 International Online Survey. Nutrients, 2020;12:1583. https://doi.org/10.3390/nu12061583 
48.Lesser IA, Nienhuis CP. The Impact of COVID-19 on Physical Activity Behavior and WellBeing of Canadians. IJERPH 2020;17:3899. https://doi.org/10.3390/ijerph17113899

49.López-Bueno R, Calatayud J, Andersen LL, BalsalobreFernández $\mathrm{C}$, Casaña $\mathrm{J}$, Casajús $\mathrm{JA}$, et al. Immediate Impact of the COVID-19 Confinement on Physical Activity Levels in Spanish Adults. Sustainability, 2020;12:5708. https://doi.org/10.3390/su12145708

50. Reyes-Olavarría D, Latorre-Román PÁ, GuzmánGuzmán IP, Jerez-Mayorga D, Caamaño-Navarrete F, Delgado-Floody P. Positive and negative changes in food habits, physical activity patterns, and weight status during COVID-19 confinement: Associated factors in the Chilean population. Int $J$ Environ Res Public Health, 2020;17:1-14. https://doi.org/10.3390/ijerph17155431

51. Romero-Blanco C, Rodríguez-Almagro J, OnievaZafra MD, Parra-Fernández ML, Prado-Laguna MDC, Hernández-Martínez A. Physical activity and sedentary lifestyle in university students: Changes during confinement due to the COVID-19 pandemic. Int J Environ Res Public Health, 2020;17:1-13. https://doi.org/10.3390/ijerph17186567

52. Ruíz-Roso MB, de Carvalho Padilha P, MatillaEscalante DC, Brun P, Ulloa N, Acevedo-Correa $\mathrm{D}$, et al. Changes of physical activity and ultraprocessed food consumption in adolescents from different countries during COVID-19 pandemic: An observational study. Nutrients, 2020;12:2289. https://doi.org/10.3390/nu12082289

53. Schuch FB, Bulzing RA, Meyer J, Vancampfort D, Firth J, Stubbs B, et al. Associations of moderate to vigorous physical activity and sedentary behavior with depressiveand anxiety symptoms in self-isolating people during the COVID-19 pandemic: A cross-sectional survey in Brazil. Psychiatry Res, 2020;292:113339. https://doi.org/10.1016/j.psychres.2020.113339

54. Sánchez-Sánchez E, Ramírez-Vargas G, AvellanedaLópez Y, Orellana-Pecino JI, García-Marín E, Díaz-Jimenez J. Eating habits and physical activity of the Spanish population during the COVID-19 pandemic period. Nutrients, 2020;12:1-12. https://doi.org/10.3390/nu12092826

55. Aubertin-Leheudre M, Rolland Y. The importance of physical activity to care for frail older adults during the COVID-19 pandemic. J Am Med Dir Assoc, 2020;21:973-6. https://doi.org/10.1016/j.jamda.2020.04.022

56.Di Stefano V, Battaglia G, Giustino V, Gagliardo A, D'Aleo M, Giannini $O$, et al. Significant reduction of physical activity in patients with neuromuscular disease during COVID-19 pandemic: the long-term consequences of quarantine. $J$ Neurol, 2021;268:20-6. https://doi.org/10.1007/s00415-020-10064-6

57.Giustino V, Parroco AM, Gennaro A, Musumeci G, Palma A, Battaglia G. Physical Activity Levels and Related Energy Expenditure during COVID-19 Quarantine among the Sicilian Active Population: A Cross-Sectional
Online Survey Study. Sustainability, 2020;12:4356. https://doi.org/10.3390/su12114356

58.Katewongsa P, Widyastari DA, Saonuam P, Haemathulin $\mathrm{N}$, Wongsingha N. The effects of the COVID-19 pandemic on the physical activity of the Thai population: Evidence from Thailand's Surveillance on Physical Activity 2020. Journal of Sport and Health Science, 2021;10:341-8. https://doi.org/10.1016/j.jshs.2020.10.001

59.Maugeri G, Castrogiovanni P, Battaglia G, Pippi R, D'Agata V, Palma A, et al. The impact of physical activity on psychological health during Covid-19 pandemic in Italy. Heliyon 2020;6:e04315. https://doi.org/10.1016/j.heliyon.2020.e04315

60. Suzuki Y, Maeda N, Hirado D, Shirakawa T, Urabe Y. Physical activity changes and its risk factors among community-dwelling Japanese older adults during the COVID-19 epidemic: Associations with subjective well-being and health-related quality of life. Int J Environ Res Public Health, 2020;17:1-12. https://doi.org/10.3390/ijerph17186591

61. Zhang X, Zhu W, Kang S, Qiu L, Lu Z, Sun Y. Association between physical activity and mood states of children and adolescents in social isolation during the COVID-19 epidemic. Int $J$ Environ Res Public Health, 2020;17:1-12. https://doi.org/10.3390/ijerph17207666

62. MattioliAV., Sciomer S, CocchiC, Maffei S, Gallina S. Quarantine during COVID-19 outbreak: Changes in diet and physical activity increase the risk of cardiovascular disease. Nutr Metab Cardiovasc Dis, 2020;30:1409-17. https://doi.org/10.1016/j.numecd.2020.05.020

63.Goethals L, Barth N, Guyot J, Hupin D, Celarier T, Bongue B. Impact of Home Quarantine on Physical Activity Among Older Adults Living at Home During the COVID-19 Pandemic: Qualitative Interview Study. JMIR Aging, 2020;3:e19007. https://doi.org/10.2196/19007

64.Martinez-Ferran M, de la Guía-Galipienso F, Sanchis-Gomar F, Pareja-Galeano H. Metabolic Impacts of Confinement during the COVID-19 Pandemic Due to Modified Diet and Physical Activity Habits. Nutrients, 2020;12:1549. https://doi.org/10.3390/nu12061549

65. Shalash A, Roushdy T, Essam M, Fathy M, Dawood NL, Abushady EM, et al. Mental health, physical activity, and quality of life in Parkinson's disease during COVID-19 pandemic. Mov Disord, 2020;35:1097-9. https://doi.org/10.1002/mds.28134

66. Yamada M, Kimura Y, Ishiyama D, Otobe Y, Suzuki M, Koyama S, et al. Effect of the COVID-19 Epidemic on Physical Activity in CommunityDwelling Older Adults in Japan: A Cross-Sectional Online Survey. J Nutr Health Aging, 2020;24:948-50. https://doi.org/10.1007/s12603-020-1424-2

67. Carter SJ, Baranauskas MN, Fly AD. Considerations for obesity, vitamin $\mathrm{D}$, and physical activity amid the COVID-19 pandemic. Obesity, 2020;28:1176-7. https://doi.org/10.1002/oby.22838

68.Pieh C, Budimir S, Probst T. The effect of age, gender, income, work, and physical activity on mental health during coronavirus disease (COVID-19) lockdown in Austria. 
Journal of Psychosomatic Research, 2020;136:110186. https://doi.org/10.1016/j.jpsychores.2020.110186

69. Shibata N, Kajikawa Y, Takeda Y, Matsushima $\mathrm{K}$. Detecting emerging research fronts based on topological measures in citation networks of scientific publications. Technovation, 2008;28:758-75. https://doi.org/10.1016/j.technovation.2008.03.009

70. Boyack KW, Klavans R. Co-citation analysis, bibliographic coupling, and direct citation: Which citation approach represents the research front most accurately?JAm SocInfSciTechnol,2010;61:2389-404. https://doi.org/10.1002/asi.21419

\section{Information about the authors:}

Mateusz Tomanek; (Corresponding Author); https://orcid.org/0000-0002-9527-2513; mtomanek@umk.pl; Faculty of Economic Sciences and Management, Nicolaus Copernicus University; ul. Gagarina 13a, 87-100, Toruń, Poland.

Andrzej Lis; https://orcid.org/0000-0003-4080-4137; andrzejlis@econ.umk.pl; Faculty of Economic Sciences and Management, Nicolaus Copernicus University; ul. Gagarina 13a, 87-100, Toruń, Poland.

Cite this article as:

Tomanek M, Lis A. Physical activity in the context of the COVID-19 pandemic: Research profiling and mapping. Physical Education of Students, 2021;25(3):136-148.

https://doi.org/10.15561/20755279.2021.0301

This is an Open Access article distributed under the terms of the Creative Commons Attribution License, which permits unrestricted use, distribution, and reproduction in any medium, provided the original work is properly cited http://creativecommons.org/licenses/by/4.0/deed.en

Received: 27.02.2021

Accepted: 10.04 .2021 ; Published: 30.06 .2021 